\title{
80 anos do Serviço Social no Brasil: marcos históricos balizados nos códigos de ética da profissão
}

\author{
80 years of Social Work in Brazil: historical \\ landmarks marked by the profession's ethical code
}

\begin{abstract}
Edistia Maria Abath Pereira de Oliveira
Professora de Ética Profissional do Curso de Serviço Social da UFPE/Recife, Brasil; pós-doutora em Serviço Social pela PUC-SP; líder do Grupo de Estudo e Pesquisa sobre Assistência Social (GEPAS).

edistia@uol.com.br

\section{Helena Lúcia Augusto Chaves}

Professora da Graduação e da Pós-Graduação em Serviço Social da UFPE/Recife, Brasil; líder do Grupo de Estudos e Pesquisas sobre Estado, Política Pública e Sociedade (GEPPS).

helena.chaves@gmail.com
\end{abstract}

Resumo: Esta reflexão destaca elementos da trajetória de 80 anos do Serviço Social no Brasil, balizados nos códigos de ética, como expressão da dinâmica processual em que a profissão foi concebida, reconceituada e renovada. O objetivo é ressaltar o status de maturidade da profissão, fundamentada no pensamento marxiano e no Projeto Ético-Político profissional, embora contraditoriamente ainda existam resquícios de sua origem, marcada pelo neotomismo e por práticas de ajustamento e ajuda social.

Palavras-chave: Serviço Social. Códigos de Ética. Projeto Ético-Político.
Abstract: This article highlights aspects of the eighty-year-old path of the Brazilian Social Work. Such a path was marked by the ethical codes as the expression of the procedural dynamics in which the profession was conceived, reconceptualized and renewed. The aim is to highlight the status of the profession maturity, based on the Marxian thought and the professional ethical and political project, although, contradictorily, there are still vestiges of its origin, marked by Neothomism as well as adjustment practices and social help.

Keywords: Social Work. Ethical codes. Ethical and political project. 


\section{Introdução}

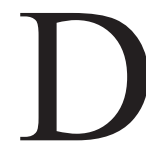

e 1936, quando da criação da primeira Escola de Serviço Social na PUC de São Paulo, a 2016, data em que a profissão completa oitenta anos no Brasil, uma história aguerrida, de lutas, de rupturas e construções, marca a trajetória do Serviço Social brasileiro. Ininterrupta e repleta de recuos e avanços, hoje é um misto dessa construção histórica, avançada pela direção social e política que se construiu em linha ascendente, atingindo um projeto profissional de maturidade acadêmica e de exercício profissional consolidado na perspectiva da renovação. Mas, também marcada por recuos, que podem ser identificados na postura de subserviência às imposições do mercado, definidas pelo conservadorismo, que possui expressão tanto no âmbito do exercício profissional como da formação, embora se caracterize como postura destoante da direção social, consolidada pelas entidades representativas da categoria. Esse "complexo itinerário histórico" (Castro, 1989, p. 18) do Serviço Social oscila entre uma prática missionária, conservadora e vinculada aos segmentos dominantes da sociedade e uma prática transformadora, renovada e comprometida com os interesses da classe trabalhadora.

Nos momentos iniciais da profissão, desde as origens até os primeiros anos da institucionalização profissional, houve forte influência da Igreja Católica, especialmente a partir das duas encíclicas papais: a Rerum Novarum, de Leão XIII, e a Quadragésimo Anno, de Pio XI. No contexto atual da profissão, a laicidade e o materialismo histórico dialético compõem o argumento central. De lá para cá a profissão passou por uma reconfiguração significativa, galgando posição extremada em relação a sua origem, mas ainda é fortemente marcada pelo sincretismo que acompanhou a sua trajetória histórica.

Essa reflexão visa contribuir com a manutenção da memória histórica do Serviço Social, mediante o destaque de alguns elementos que se constituem em marcas e marcos dessa história. Dentre as marcas foram destacadas aquelas que representam momentos relevantes nessa composição histórica e que imprimiram a face dessa profissão. Dentre os marcos foram enfocados os códigos de ética, uma vez que estão intrinsecamente ligados à dinâmica do processo histórico da profissão, no que se refere aos aspectos conjunturais, estruturais, teóricos, filosóficos e metodológicos. 
A dialética social que organiza o processo da profissão, na sua gênese e nas suas transformações sucessivas, perpassa o arcabouço teórico-metodológico, que estrutura, forma e funda a profissão.

\section{A profissão de Serviço Social no capitalismo contemporâneo: reflexões sobre os marcos fundantes e a gênese da profissão no Brasil}

Considera-se que as revoluções europeias do século XVIII constituem a base para a consolidação do capitalismo e, paralelamente, à medida que rompem com sistemas tradicionais de forma de organização social, representam o solapamento de costumes e instituições vigentes até então. Introduzem, por outro lado, novos hábitos e estratégias de sobrevivência. As pequenas cidades se complexificam e crescem com a emigração do campo para a cidade. As consequências imediatas da instauração do modo de produção capitalista, impresso na rápida industrialização e urbanização, resultam no acirramento da questão social, que se expressa em fenômenos como a prostituição, o alcoolismo a violência e o suicídio, que, por sua vez, são manifestações da principal contradição do modo de produção capitalista: a socialização do trabalho versus a privatização da riqueza, aspecto que caracteriza diferentes formas de organização da produção e do trabalho assumidos historicamente - taylorismo, fordismo e toyotismo. Isso vai requerer, necessariamente, análise aprofundada das expressões do capitalismo em sua relação com o avanço/retrocesso das forças produtivas, bem como a definição de propostas de intervenção para transformação dessa realidade. Tendo em vista uma ação nesse contexto, são necessários profissionais aptos a realizarem a leitura da realidade e dos modos de organização da vida em sociedade, com formação específica, ou seja, baseada nos elementos constitutivos da convivência e sobrevivência sociais e nos fatores que dela decorrem.

Entre outras profissões de natureza social, o Serviço Social é demandado nesse contexto, organizando-se em instituições da sociedade, na perspectiva de ajudar e assistir o "necessitado", o "deficiente" e o "desajustado" socialmente. Lima (1983, p. 50) ressalta que o objetivo implícito desses serviços era "controlar os conflitos ou minimizar as disfuncionalidades sociais de modo mais sistemático e racional". 
O Serviço Social, como profissão institucionalizada, configura-se no cenário mundial a partir da década de 1920, após a Primeira Guerra Mundial, quando se caracteriza de forma mais evidente e abrangente a questão social, bem como formas de organização da classe trabalhadora, que contextualizam o surgimento de movimentos especialmente europeus de ação social, cuja finalidade era a difusão de ideias políticas.

Diferentemente do que ocorre nos países da Europa, a estrutura em que se fundamenta a origem do Serviço Social nos Estados Unidos caracteriza-se por um caráter pragmático, procurando solução para os conflitos sociais, por meio de ações práticas e na consideração de aspectos subjetivos do indivíduo (Lima, 1983).

Inserida nesse contexto mundial, nas primeiras décadas do século XX o aguçamento da questão social na América Latina - expressão das contradições embutidas no seu processo de formação capitalista - começa a exigir respostas a serem implementadas pela sociedade civil, especialmente pela Igreja e pelo Estado, através de políticas sociais incipientes.

Tendo em vista a sua operacionalização, são formados serviços, os quais, para serem racionalizados e sistematizados, vão exigir profissionalização, oferecida por escolas especializadas em Serviço Social, emergentes em vários países da América Latina.

No Brasil, após a proclamação da República (1889) e o fim do padroado (1890), quando houve a separação entre Estado e Igreja, estabeleceu-se um Estado não confessional e, sob o regime da liberdade religiosa, igualou-se a Igreja Católica a outras instituições religiosas. Nesse contexto organizou-se no Rio de Janeiro um movimento significativo de expansão e fortalecimento da presença da Igreja na sociedade. O então arcebispo do Rio de Janeiro, dom Sebastião Leme, liderou um movimento cujo objetivo maior era afirmar e difundir o ideário cristão e "recatolizar" o país. Desse movimento foi fundada, em 1921, a revista A Ordem, e em 1922, o Centro Dom Vital, ambos sob a direção de Jackson de Figueiredo. A publicação da revista, de periodicidade mensal, era responsabilidade do departamento editorial do Centro Dom Vital. A revista foi extinta em 1990, sendo editada durante 69 anos.

Posteriormente, em 1932, foi fundado o Centro de Estudos e Ação Social (CEAS), voltado para a formação técnica especializada, a partir do qual surgiu 
a primeira Escola de Serviço Social na PUC de São Paulo, em 1936, vinculada inicialmente à Ação Social, com formação baseada na doutrina social da Igreja Católica. Nesse contexto, destacam-se movimentos como, por exemplo: Juventude Estudantil Católica (JEC), Juventude Operária Católica (JOC) e Juventude Universitária Católica (JUC). Em 1937, foi fundada a segunda Escola de Serviço Social na PUC do Rio de Janeiro, e em 1940, a terceira no Recife.

A perspectiva de ação para o Serviço Social, nesse primeiro momento, é bem delimitada. Restringe-se ao atendimento individual, a partir da concepção de sociedade, que caracteriza o indivíduo em condições estruturais de pobreza, como pessoa fraca, desajustada e incapaz, que precisa de ajuda especial. Adota-se a metodologia de caso, grupo ou comunidade, como formas de implementar a intervenção social, sem objetivar, contudo, uma análise na estrutura social. A pobreza é expressa estatisticamente, vista sem o estabelecimento de relação com a forma de organização social. Embora os assistentes sociais reconheçam que as leis de amparo social, existentes para proporcionar respostas à pobreza, fossem insuficientes, creditam à falta de educação ou a desvios morais da população a incapacidade de prover sua subsistência ou viver nas condições observadas.

Mas embora tenha sido originada com esse posicionamento em relação à realidade social e tenha permanecido durante um longo período de sua história, o aprofundamento das questões pertinentes ao campo da formação em Serviço Social foram impulsionando um conhecimento sobre as raízes históricas de desencadeamento desses fenômenos sociais, que se constituem em demanda para a profissão e alavancaram a profissionalização do Serviço Social em outros moldes.

\section{As particularidades dos Códigos de Ética profissional na trajetória do Serviço Social brasileiro: de 1947 a 1993 - uma história de transformações}

A partir de 1940, inicia-se um debate, em nível internacional, através da União Católica Internacional de Serviço Social (UCISS), sediada na Bélgica, quando é proposta a elaboração de um código de moral para orientar a prática 
profissional, de acordo com a doutrina social. A visão de homem e de mundo subjacente a esse Código é inspirada na filosofia neotomista, através da encíclica Rerum Novarum, que fundamentou o Código Social de Malinas, publicado em Bruxelas, Bélgica, em 1927, e que vai também influenciar a formação de diversos documentos em vários países europeus no sentido de orientar a fé e a moral cristã. Fundamentado em princípios metafísicos, a sociedade e as relações sociais econômicas e políticas são exortadas a realizar suas ações segundo as leis da fé.

O primeiro Código de Ética Profissional do(a) Assistente Social elaborado/ promulgado em 1947 é sucinto (CFESS, 2016), foi influenciado pela visão europeia, impregnado de valores cristãos, sem mediação do Estado e, portanto, sem respaldo jurídico. Visava orientar a prática e conferir status de profissão ao Serviço Social, que não era ainda regulamentada como categoria profissional.

De acordo com Iamamoto e Carvalho (2002, p. 218-219):

[...] essa fase de implantação, verifica-se a existência de um projeto teórico de intervenção nos diversos aspectos da vida do proletariado, tendo em vista a reordenação do conjunto da vida social. O aprofundamento do capitalismo gera uma série de necessidades, que exigem profundas transformações na vida social [...] e as práticas incipientes dos Assistentes Sociais orienta-se para a intervenção na reprodução material do proletariado e para sua reprodução enquanto classe. $\mathrm{O}$ centro de suas preocupações é a família, base da reprodução material e ideológica da Força de Trabalho.

Em relação à formação profissional, resgata Aguiar, citando Ferreira em artigo, de 1944:

A formação científica se dará através das disciplinas científicas como a Sociologia, Psicologia, e Biologia e também da Moral. E deve proporcionar um conhecimento "exato do homem e sociedade, de todos os problemas que dele se originam e neles se refletem" [...] A formação técnica é a formação específica do Assistente Social. Consiste no estudo das teorias do Serviço Social então existentes e sua adaptação à nossa realidade. [...] A formação prática é a aprendizagem do "como fazer" na realidade das diferentes instituições com que os futuros assistentes sociais mantinham contatos. (Ferreira, apud Aguiar, 1995, p. 32-33) 
Nadir Kfouri, estudiosa do Serviço Social, ressalta no Segundo Congresso Pan-Americano, em 1949, realizado no Rio de Janeiro, que no início a prática profissional se constituía de visitas realizadas a obras sociais e às famílias necessitadas. Posteriormente, as escolas organizaram estágios com supervisão. No que se refere à formação pessoal, a preocupação era o desabrochar da personalidade integral do aluno. Devia-se proporcionar ao assistente social uma formação moral sólida.

Pereira citada por Aguiar (1995, p. 33), destaca, também, em relação à prática profissional:

Sem uma formação moral muito solidamente edificada sobre uma base de princípios cristãos, a atividade da assistente será falha, porque lhe faltarão os elementos que garantem uma ação educativa, que é visada pelo Serviço Social.

Esse será um dos aspectos importantes na "formação doutrinária" dos alunos, como se pode ainda perceber:

Além das atividades normais da escola, existem alguns meios específicos: os círculos de estudo e a orientação individual. Os círculos de estudo são reuniões, onde estão os alunos e os orientadores do curso. Nessas reuniões, são discutidos pontos das várias disciplinas, bem como ajudar a "desenvolver o raciocínio e o despertar o sentido social”. Para realização deste último ponto, são discutidos e analisados os problemas da realidade e as soluções possíveis dentro da visão cristã. Utiliza-se o método da Ação Católica: ver, julgar e agir. [...] Para a formação doutrinária, serão básicas aulas de Doutrina Católica e de Moral. Para que uma escola de Serviço Social possa realizar bem sua tarefa requer uma formação doutrinária definida. A formação doutrinária é importante, pois toda ação requer normas, princípios, diretrizes. Requer uma ideologia (Pereira, apud Aguiar, 1995, p. 34)

A ideologia escolhida, proposta, determinada pelas injunções em que estava circunstanciado o Serviço Social, era a da doutrina social da Igreja Católica. Deve-se ressaltar que a questão de fundamentos, de princípios, esteve sempre presente na formação do assistente social. Historicamente, sua prática 
foi baseada não apenas na caridade, em princípios religiosos ou no assistencialismo, mas, como dizem Iamamoto e Carvalho (2002, p. 221-222), constituiu

[...] uma forma de intervenção ideológica, que se baseia no assistencialismo como suporte de uma atuação cujos efeitos são essencialmente políticos: o enquadramento das populações pobres e carentes, o que engloba o conjunto das classes exploradas.

Analisando ainda o discurso das pioneiras do Serviço Social:

[...] demonstra a certeza de estarem investidas de uma missão de apostolado, decorrente não só da adesão aos princípios católicos, como de sua origem de classe. Elementos que legitimam sua autoridade num empreendimento de levantamento moral de uma população que vegeta no pauperismo e no rebaixamento moral (Iamamoto e Carvalho, 2002, p. 223)

Os princípios e as diretrizes pontuados no Código de 1947 (CFESS, 2016) refletem os fundamentos destacados na formação profissional, frisando a importância da moral e da ética descolada dos processos históricos e sociais, orientando para a prática do bem, destacando que a ação do Serviço Social não se caracteriza apenas pela ajuda material que presta, mas também pela ajuda às pessoas desajustadas ou empenhadas no desenvolvimento da própria personalidade.

Nesse contexto, deve-se salientar a influência da Associação Brasileira de Ensino de Serviço Social (ABESS), que, fundada em 1946, sob a égide da Igreja Católica, irá promover sistematicamente convenções anuais, tendo como pauta a formação do(a) assistente social.

Nesse período, merece destaque também o intercâmbio, feito com escolas americanas, através de programa de bolsas de estudo, iniciado desde meados da década de 1940 até a metade dos anos 1950. A bibliografia então utilizada pelos alunos(as) brasileiros(as), de cunho positivista e funcionalista, contribuiu significativamente para a perspectiva adotada pelo Serviço Social no Brasil. Dos Estados Unidos foram importados também métodos e técnicas, sem que se estabelecesse crítica e adaptação que garantissem adequação ou compatibilização à realidade brasileira. 
Após dezoito anos de vigência, o Código de Ética de 1947 (CFESS, 2016) foi reformulado, tendo como motivo a regulamentação jurídica da profissão, as transformações conjunturais do país e o próprio questionamento formulado sobre a metodologia do Serviço Social e questões teleológicas. O conteúdo e os princípios do novo código continuam tendo por base as influências dogmáticas do neotomismo. Prevalece a visão do homem como ser abstrato, universal e a compreensão da sociedade, na qual os fatos ocorrem isoladamente, como processos evolutivos que independem da ação humana. A solidariedade, o amor ao próximo e a doação permanecem sendo os valores propulsionadores do Serviço Social.

Em 1967 foi realizado o Seminário de Araxá, primeiro de uma série, que terá lugar a partir desse momento e que vai culminar com o que, em Serviço Social, convencionou-se chamar de "Movimento de Reconceituação". Esses seminários foram promovidos pelo Centro Brasileiro de Cooperação e Intercâmbios de Serviços Sociais (CBCISS).

O documento resultante desse primeiro seminário representa um esforço no sentido de elaboração de uma teoria do Serviço Social, ou seja, indicar seus objetivos, suas funções e a adequação da metodologia às funções. Os elementos consubstanciados nesse seminário destacam ainda a promoção humana e a conscientização como fundamentos que devem orientar o desenvolvimento no seu sentido global. Apesar da tentativa de redefinir a profissão, permanece, como posteriormente indica Netto, a presença do tradicional nas novas perspectivas. E, segundo ele, os princípios e postulados "derivam diretamente do neotomismo, com o seu eticismo inteiramente abstrato e a-histórico" (Netto, 1991, p. 169). Citando Souza, Netto frisa acerca do documento e seus pressupostos éticos: "se colocam num nível tal de abstração e idealização que chegam a não atentar para o caráter histórico e temporal dos valores humanos" (Souza, apud Netto, 1991, p. 169).

No tocante à formação profissional, nessa época começa a haver a incorporação, pelas universidades públicas, de grande parte das escolas que se mantinham isoladas, o que amplia as bases de informação e proporciona intercâmbio novo a docentes e discentes.

Tendo em vista atender as determinações do momento histórico e expressar elementos das reflexões originárias dos seminários de Araxá (1967) e de 
Teresópolis (1970), foi promulgado outro Código de Ética em 1975 (CFESS, 2016). Nesse sentido, Netto refere que os objetivos propostos pelo encontro de Araxá, em relação à teoria do Serviço Social, não são alcançados:

[...] o documento reduz a teorização a "uma abordagem técnica operacional em função do modelo básico de desenvolvimento". (CBCISS, apud Netto, 1991, p. 176)

Nestes termos, Netto conclui:

Entretanto, nem por este artifício se escamoteia a teoria: se ela vem revestida pela tecnicalidade, não está evidentemente cancelada; bem ao contrário: existe uma clara dominância teórica a informar o Documento de Araxá — é o referencial estrutural-funcionalista. (Netto, 1991, p. 176)

Em relação ao seminário de Teresópolis, segundo analistas desses encontros, houve uma preparação prévia através de documentos, cuja temática se centralizava na metodologia. Esse seminário, no entanto, veio a corroborar mais as questões relacionadas ao eixo filosófico — neotomista e metodológico — positivista/funcionalista. Nessa perspectiva, houve a integração da ação do Serviço Social no processo de desenvolvimento brasileiro, com uma proposta de operacionalização técnica a favor do modelo socioeconômico vigente no país.

O Código de Ética Profissional do(a) Assistente Social de 1975 (CFESS, 2016) referenda essas perspectivas, bem como a formação e a prática profissionais. Caracteriza-se, ainda, por conteúdo insuficiente no que se refere às questões fundamentais da profissão. Reconhece ainda o Estado como gestor do bem comum, numa perspectiva neotomista e acrítica. Como decorrente dos elementos pontuados no Código, o Serviço Social assume a prática dentro de uma perspectiva de transformação e participação social. Esses princípios, entretanto, apenas reproduzem a ordem estabelecida, uma vez que não enfatizam a capacidade crítica e transformadora do homem como ser histórico.

As insatisfações e o processo de luta enfrentada, desde a metade da década de 1960, levam à constatação de que a concepção da profissão contida e refletida no Código de 1975 (CFESS, 2016) já não atendem às demandas profissionais, ao movimento dinâmico que atravessa a sociedade naquele período. 
Paralelamente, observa-se o questionamento sobre o Serviço Social tradicional, desencadeado por fatos que ocorreram e se circunscrevem na América Latina, mas se explicam pelo

O tensionamento das estruturas sociais do mundo capitalista, quer nas suas áreas centrais, quer nas periféricas, ganhou uma nova dinâmica; num contexto de desanuviamento das relações internacionais (superados já os temos da Guerra Fria), gestou-se um quadro favorável para a mobilização das classes sociais subalternas em defesa dos seus interesses imediatos. [...] Nas suas expressões menos consequentes, estes movimentos põem em questão a racionalidade do Estado burguês e suas instituições; nas suas expressões mais radicais, negam a ordem burguesa e o seu estilo de vida. Em qualquer dos casos, recolocam em pauta as ambivalências da cidadania fundada na propriedade e redimensionam a atividade política, multiplicando os seus sujeitos e as suas arenas. Ora, este é o cenário mais adequado para promover a contestação de práticas profissionais como as do Serviço Social "tradicional". (Netto, 1991, p. 143)

O autor ressalta ainda que o mesmo processo ocorre em outras profissões, sobretudo aquelas institucionalizadas e que atuam na esfera da reprodução das relações sociais (Netto, 1991).

Nessa conjuntura, inicia-se uma série de debates, que tem o seu ápice no III Congresso de Serviço Social, em São Paulo (1979), conhecido como Congresso da Virada, que se constituiu em um marco histórico fundamental na trajetória do Serviço Social brasileiro, a partir do qual a aproximação com a tradição marxista configura-se como um projeto em disputa pela direção ideopolítica e teórico-metodológica da profissão.

O Serviço Social passa por um profundo processo de renovação, repercutindo na sua produção teórica e prática, refletindo a própria insatisfação social que caracterizou os movimentos sociais nos anos 1978-1980. Esse processo de renovação, segundo Netto (1991, p. 154), constituiu-se de três direções principais. A primeira, denominada "perspectiva modernizadora para as concepções profissionais", empenhou-se em adequar o instrumental técnico e operacional do Serviço Social às estratégias do desenvolvimento capitalista no período pós-64, tendo os textos dos seminários de Araxá e Teresópolis como marcos da 
renovação para a categoria profissional. Essa perspectiva teve sua hegemonia posta em questão a partir de meados dos anos 1970. A segunda direção foi designada como "perspectiva de reatualização do conservadorismo" (Netto, 1991, p. 157), na qual se condensava o segmento mais avesso às mudanças, apresentando proposições de tendências irracionalistas, fundamentadas na fenomenologia e na psicologia, enfatizando as dimensões da subjetividade e respaldando o exercício profissional no campo da "ajuda psicossocial". Essa direção do desenvolvimento profissional evidenciou-se em meados dos anos 1970 e teve uma expressão de menor envergadura no âmbito profissional. A terceira direção foi a perspectiva proposta como "intenção de ruptura com o Serviço Social 'tradicional"” (Netto, 1991, p. 159), que visava romper com a tradição positivista e com o reformismo conservador, tanto no que se refere à matriz teórica, como aos paradigmas conservadores de intervenção social, fundamentado na crítica sistemática aos seus arcabouços teóricos, metodológicos e ideológicos. Essa direção fundamenta-se na tradição marxista, formula o conhecido "Método BH" na primeira metade da década de 1970 e polemiza o debate profissional na primeira metade da década de 1980, caracterizando-se por uma retórica politizada, tendo como mérito mais evidente a qualificação da profissão no debate acadêmico e político.

A partir de então, desencadeia-se o processo de consolidação da profissão, entendida como especialização do trabalho coletivo, inserida na divisão sociotécnica do trabalho, tendo como objeto de intervenção a questão social, ao mesmo tempo que rompe com a sua característica acrítica e a-histórica, adotando-se o pensamento marxiano como inspiração filosófica, parâmetro da ação profissional e da análise das relações de produção capitalista.

Vale ressaltar que no primeiro momento de aproximação com a teoria marxista, os estudos e leituras foram impregnados de equívocos, refletindo nas perspectivas teórica, metodológica e filosófica adotadas, inclusive sob o ponto de vista da ética. Mas esse fato, embora consolide posições no âmbito do conservadorismo, não impediu o avanço no aprofundamento da perspectiva marxiana no sentido da sua compreensão e possibilidades de leitura da realidade. Nessa perspectiva, compreende-se o homem como um ser concreto, histórico e social, contextualizado em determinada sociedade, considerada complexa e contraditória. 
Nesse contexto, torna-se inevitável uma discussão em torno do Código de Ética de 1975 (CFESS, 2016), tendo em vista sua insuficiência em analisar e gerar formas compatíveis e coerentes de conhecimento e intervenção profissional, envolvendo a categoria e os diversos órgãos da classe, culminando com a reformulação e a aprovação do novo código em 9 de maio de 1986.

Na introdução do Código de Ética de 1986 está pontuado:

A nova ética é resultado da inserção da categoria nas lutas da classe trabalhadora e, consequentemente, de uma nova visão da sociedade brasileira. Neste sentido, a categoria através das suas organizações, faz uma opção clara por uma prática profissional vinculada aos interesses desta classe. (CFESS, 2016, p. 1)

A ética passa a ser entendida no movimento dinâmico da história, determinado pelas relações sociais de produção. Dessa forma, o Código de Ética compõe-se não apenas de elementos que embasam a formação profissional no campo do dever ser, mas de elementos referentes ao exercício profissional. $\mathrm{O}$ compromisso com a classe trabalhadora se apresenta como o princípio da nova ética, que a partir desse código aponta para a necessidade de superação da visão acrítica, que se coloca acima dos interesses de classe e acredita em valores universais. Esse entendimento contido no código configura uma oposição ao neotomismo, aproximando-se do pensamento marxiano, defendido pela vertente de intenção de ruptura, cuja politização demarca o posicionamento da prática profissional, voltada aos interesses dos usuários, entendidos como sujeitos históricos pertinentes a uma classe social.

Os termos desse código e dos eixos temáticos da formação profissional já vinham sendo discutidos pela categoria e tornaram-se evidentes na $24^{\mathrm{a}}$ Convenção da Associação Nacional de Ensino de Serviço Social, realizada em Niterói (RJ), em 2/9/1985. A convenção incluiu palestras sobre conjuntura nacional, formação profissional, teoria, método e história. É o início de uma luta da categoria por um projeto:

[...] profissional crítico que, respaldado na melhor herança clássica e contemporânea do pensamento social na modernidade, seja capaz de responder aos desafios 
colocados pela História à profissão como atividade inscrita na divisão social do trabalho, seja do ponto de vista do desvelamento da sociedade, da identidade da própria profissão e das respostas teórico-práticas no âmbito profissional que se desdobrem em elementos impulsionadores do movimento de superação desse modo de organização da vida e do trabalho em sociedade. (ABESS, 1986, p. 4)

São, ainda, destacados como exigência do processo de formação profissional alguns aspectos, dentre os quais salientam-se:

Propiciar condições objetivas para a formação de assistentes sociais críticos, comprometidos e conscientes [...]; Delimitar, com referência básica, uma proposta de Serviço Social que, de fato, configure alternativas de ação profissional na dinâmica contraditória da atual conjuntura brasileira [...]; Desenvolver uma formação básica que de fato instrumentalize metodologicamente o assistente social para o exercício profissional na dinâmica contraditória da sociedade brasileira [...]; Desenvolver uma política de capacitação docente como suporte básico na redefinição do processo de formação profissional do assistente social. (Carvalho, 1986, p. 37-41)

Segundo Barroco, embora o código ora focalizado tenha avançado nos aspectos da superação da imparcialidade, neutralidade, dos valores metafísicos e da própria prática profissional, no que diz respeito ao estímulo à pesquisa e à crítica da realidade:

O Código expressa uma concepção ética mecanicista; ao derivar, imediatamente, a moral da produção econômica e dos interesses de classe, não apreende as mediações, particularidades e dinâmicas da ética. Ao vincular, mecanicamente, o compromisso profissional com a classe trabalhadora sem estabelecer a mediação dos valores próprios à ética, reproduz uma visão tão abstrata quanto a que pretende negar. (Barroco, 2001, p. 176-177)

Alguns aspectos são ainda ressaltados por outros estudiosos, em relação ao questionamento do código, o que levou a uma nova reformulação.

A reflexão ética, desenvolvida na reelaboração do código de 1986, procurou se embasar em categorias universalizantes sob o ponto de vista de inclusão das diversas classes sociais e na dimensão ontológica do ser social, da sua forma 
de ser e reproduzir-se socialmente e, sobretudo, na elaboração sistematizada do que se convencionou chamar de Projeto Ético-Político profissional.

Procurou, também, instrumentalizar a categoria profissional frente aos embates e desafios da conjuntura nacional, inserida nos processos de globalização e do neoliberalismo, que vão produzir grandes e imprevisíveis mudanças nas relações sociais de produção e na organização da vida social no momento atual. Nesse sentido, um novo código foi aprovado em 13 de março de 1993 (CFESS, 2016), o qual ainda está em vigor. Em 1994, 1996 e 2011, esse código sofreu alterações introduzidas respectivamente pelas Resoluções CFESS ns. 290/1994, 293/1994, 333/1996 e 594/2011. A última edição, revista e ampliada, incorpora as alterações do código, discutidas e aprovadas no $39^{\circ}$ Encontro Nacional CFESS/CRESS, realizado em setembro de 2010 na cidade de Florianópolis (SC), consignadas na Resolução CFESS n. 594, de 21 de janeiro de 2011, publicada no DOU em 24 de janeiro do mesmo ano.

Foram incorporados ao código correções formais, que se referem à:

[...] incorporação das novas regras ortográficas da língua portuguesa, assim como à numeração sequencial dos princípios fundamentais do Código e, ainda, ao reconhecimento da linguagem de gênero, adotando-se em todo o texto a forma masculina e feminina, simultaneamente. Essa última expressa, para além de uma mudança formal, um posicionamento político, tendo em vista contribuir para negação do machismo na linguagem, principalmente por ser a categoria de assistentes sociais formada majoritariamente por mulheres. (CFESS, 2016, p. 13)

As mudanças realizadas, referentes ao conteúdo:

[...] foram relativas à modificação de nomenclatura, substituindo o termo "opção sexual" por "orientação sexual", incluindo ainda no princípio XI a "identidade de gênero", quando se refere ao exercício do serviço social sem ser discriminado/a nem discriminar por essa condição, juntamente com as demais condições já explicitadas no texto. Essas alterações são de suma importância, pois reafirmam princípios e valores do nosso Projeto Ético-Político e incorporam avanços nas discussões acerca dos direitos da população LGBT pela livre orientação e expressão sexual. Portanto, as mudanças aqui expressas são resultado de discussões no 
âmbito do Conjunto CFESS/CRESS, em especial na temática da ética e dos direitos humanos. (CFESS, 2016, p. 13-14)

A abrangência e o significado implícitos no conteúdo dos princípios/categorias expostos nesse código indicam o arcabouço conceitual que contém e propõe, sugerindo também indagação acerca do significado, da interpretação que lhe vem sendo atribuída pelos componentes da profissão, pelo exame que desses princípios realizam, considerando que representados de forma abstrata, no tocante à realidade social, podem levar à elaboração de práticas inconsistentes, pouco significativas no que se refere aos objetivos da profissão. Nesse sentido é que se indaga: como os princípios do Código de Ética profissional em vigor podem ser viabilizados em uma sociedade que apresenta características tão adversas ao seu cumprimento? Como podem orientar a formação profissional e instrumentalizar a prática?

Para Barroco (1999, p. 129):

A ética profissional é uma dimensão da profissão vinculada organicamente às dimensões teórica, técnica, política e prática. [...] Esfera teórica. Trata-se das orientações filosóficas e teórico-metodológicas que servem de base às concepções éticas profissionais, com seus valores, princípios, visão de homem e sociedade. Esfera moral prática. Diz respeito: a) ao comportamento prático individual dos profissionais relativos às ações orientadas pelo que se considera bom/mau, aos juízos de valor, à responsabilidade e compromisso social, à autonomia e consciência em face das escolhas e das situações de conflito; b) ao conjunto das ações profissionais em sua organização coletiva, direcionada teleologicamente para a realização de determinados projetos com seus valores e princípios éticos. Esfera normativa. Expressa no Código de Ética Profissional, exigido, por determinação estatutária, de todas as profissões liberais. Trata-se de um código moral que prescreve normas, direitos, deveres e sanções determinadas pela profissão, orientando o comportamento individual dos profissionais e buscando consolidar um determinado projeto profissional com uma direção social explícita.

A ética profissional, como se observa através da referência citada, está intrinsecamente ligada à ação profissional, no sentido de lhe subsidiar e orientar sob o ponto de vista dos princípios, sua fundamentação e possíveis mediações. 
Com os avanços teóricos, metodológicos e políticos acumulados desde a década de 1980 e a compreensão dos fundamentos de uma ética de ruptura alcançada na década de 1990, foram reunidas as condições para a materialização do Projeto Ético-Político profissional, marcado pelo enfrentamento e pela denúncia do conservadorismo profissional. Inscreve-se no marco do Código de Ética da profissão e pode ser caracterizado como:

[...] a auto-imagem de uma profissão, elegem os valores que a legitimam socialmente, delimitam e priorizam seus objetivos e funções, formulam os requisitos (teóricos, institucionais e práticos) para o seu exercício, prescrevem normas para o comportamento dos profissionais e estabelecem as balizas da sua relação com os usuários de seus serviços, com as outras profissões e com as organizações e instituições sociais, privadas e públicas (entre essas, também e destacadamente com o Estado, ao qual coube, historicamente, o reconhecimento jurídico dos estatutos profissionais). (Netto, 1999, p. 95)

Nesse processo, a aproximação inicial com a tradição marxista e o aprofundamento da interlocução com o pensamento marxiano forneceram o alicerce teórico-metodológico para apreender a realidade sob uma perspectiva de totalidade, e desde então vem sendo construído um processo de hegemonia contra o pragmatismo, o conservadorismo e a suposta neutralidade defendida pelo Serviço Social tradicional.

A discussão no âmbito da formação profissional em Serviço Social desencadeia a partir da década de 1990 e, sobretudo, após a aprovação do código de 1993, um amplo debate, concretizando-se nas Diretrizes Curriculares/96, as quais compõem fundamento essencial à materialização do Projeto Ético-Político.

O conjunto de consequências observadas no mundo do trabalho, provocadas pela adoção dos mecanismos da reestruturação produtiva, como resultado do neoliberalismo, recai também no Serviço Social no âmbito da sua demanda profissional, reduzindo-a e levando profissionais a subempregos à margem do emprego formal. É nesse quadro que se orienta e se redefine a formação de um novo perfil de profissional, considerando as novas demandas, e o novo cenário que se estrutura com a perspectiva de atuação em organizações não governamentais - conselhos de direitos, assessorias e consultorias — requer formação 
que corresponda à complexidade que constitui o mundo do trabalho e, por outro lado, corresponda ao ideário profissional explicitado no Código de Ética. Portanto, torna-se indispensável a aquisição e o desenvolvimento de competências teórico-práticas e ético-políticas, aliadas ao acervo de conhecimento produzido pela profissão e às instâncias representativas da categoria profissional. Nessa perspectiva, foram elaborados os princípios que, através de um conjunto de diretrizes, com base comum, determinam a fundamentação para a formação profissional.

Os princípios indicados para a formação profissional procuram estabelecer sintonia com os princípios do Código de Ética da profissão. Objetivam formar e qualificar profissionais críticos em relação à realidade social, assegurar um processo de aprendizagem articulado entre ensino, pesquisa e extensão, visando instrumentalizá-los no sentido da construção de exercício profissional coerente e ético.

A partir dessas diretrizes foram estabelecidas as bases para a elaboração dos currículos, que priorizaram a capacitação teórico-metodológica, ético-política e técnico-operativa, tendo em vista:

1. Apreensão crítica do processo histórico como totalidade; 2. investigação sobre a formação histórica e os processos sociais contemporâneos que conformam a sociedade brasileira, no sentido de apreender as particularidades da constituição e desenvolvimento do capitalismo e do Serviço Social no País; 3. apreensão do significado social da profissão desvelando as possibilidades de ação contidas na realidade; 4. apreensão das demandas — consolidadas e emergentes — postas ao Serviço Social via mercado de trabalho, visando a formular respostas profissionais que potenciem o enfrentamento da questão social, considerando as novas articulações entre público e privado; 5 . exercício profissional cumprindo as competências e atribuições previstas na legislação profissional em vigor. (ABESS/ CEDEPSS, 1997, p. 62)

Convenções da Associação Brasileira de Ensino e Pesquisa em Serviço Social (Abepss) foram realizadas com o objetivo de socializar as diretrizes e, a partir daí, as escolas formularem seus currículos e implantarem seu projeto pedagógico. 
Como destacado por vários estudiosos da profissão, atualmente, além de um acúmulo de bibliografia, vem sendo sistematizado elementos para a superação dos aspectos limitantes da formação profissional, além de que, a partir da reforma de currículos, se observa intenso movimento no sentido de promover um aprofundamento das questões relacionadas à prática profissional. Conferências, encontros, cursos, inclusive de capacitação à distância, além do incentivo à produção de conhecimento através de especializações, mestrado e doutorado, vêm buscando contextualizar questões da profissão, clarificando-as, no sentido da sua objetivação e da superação de práticas defasadas e obsoletas.

A conjuntura atual impõe questões que colidem diretamente com o nosso Projeto Ético-Político. A aglutinação das forças conservadoras, objetivando reforçar ajustes de cunho neoliberal numa perspectiva cada vez mais agressiva. Nesse sentido, é cada vez mais relevante aguçarmos a nossa crítica e nos posicionarmos valentemente contra as investidas que pretendem destruir os direitos já garantidos e as possibilidades da categoria profissional de contribuir com a construção de uma sociedade humana e justa nos marcos de outro modo de produção.

\section{Considerações finais}

O amadurecimento do projeto profissional do Serviço Social, a partir do aprofundamento de estudos e pesquisas na perspectiva marxiana, compõe a história de afirmação intelectual da profissão e estrutura uma direção hegemônica no que concerne aos fundamentos teórico-metodológicos, que orientam a formação profissional, a prática profissional e a organização política do conjunto da categoria e dos estudantes, nas respectivas entidades representativas, desencadeando o processo de construção do Projeto Ético-Político profissional. Esse projeto se configura nos documentos estruturantes do Serviço Social, embora transcenda a materialidade desses instrumentos de formalização da profissão no âmbito regulatório, constituídos pela Lei de Regulamentação da Profissão — Lei n. 8.662, de 7 de junho de 1993 —, pelo Código de Ética Profissional de 1993 e pelas Diretrizes Curriculares (ABESS/CEDEPSS, 1997). Esses instrumentos normativos, construídos nos últimos trinta anos no seio da 
categoria, são a materialização do Projeto Ético-Político profissional, embora esse projeto não se restrinja a essa dimensão, que se refere ao marco regulatório em vigor, o qual dá sustentação legal ao exercício profissional dos(as) assistentes sociais. Pelo contrário, fortalecem e respaldam as ações profissionais na direção de um projeto em defesa dos interesses da classe trabalhadora e que se articula com as lutas sociais por direitos na construção de outro projeto de sociedade, na qual não exista exploração do homem pelo homem, nem exploração da natureza até seu esgotamento.

Nessa trajetória de 80 anos do Serviço Social no Brasil, a aproximação inicial com a tradição marxista e o aprofundamento da interlocução com o pensamento marxiano forneceram o alicerce teórico-metodológico para apreender a realidade sob uma perspectiva de totalidade e desde então vem sendo construído um processo de hegemonia contra o pragmatismo, o conservadorismo e a suposta neutralidade defendida pelo Serviço Social tradicional.

Recebido em 21/6/2016 - Aprovado em 25/10/2016

\section{Referências bibliográficas}

AGUIAR, A. G. Serviço Social e filosofia: das origens a Araxá. 5. ed. São Paulo: Cortez, 1995.

ASSOCIAÇÃO BRASILEIRA DE ENSINO DE SERVIÇO SOCIAL (ABESS). O processo de formação profissional do assistente social. Cadernos ABESS, São Paulo, Cortez, n. 1, 1986.

; CENTRO DE DOCUMENTAÇÃO E PESQUISA EM POLÍTICAS SOCIAIS E SERVIÇO SOCIAL (CEDEPSS). Formação profissional: trajetórias e desafios. Cadernos ABESS, São Paulo, Cortez, n. 7, edição especial, 1997.

BARROCO, M. L. Os fundamentos sócio-históricos da ética. Capacitação em Serviço Social e política social: crise contemporânea, questão social e Serviço Social, Módulo 2. Brasília: Cead/UnB-CFESS-ABEPSS, 1999. p. 120-136. 
BARROCO, M. L. Ética e Serviço Social: fundamentos ontológicos. São Paulo: Cortez, 2001.

CARVALHO, A. M. P. de. O projeto da formação profissional do assistente social na conjuntura brasileira. Cadernos ABESS, São Paulo, Cortez, n. 1, p. 17-42, 1986.

CAStro, M. M. História do Serviço Social na América Latina. 3. ed. São Paulo: Cortez/Celats, 1989.

CONSELHO FEDERAL DE SERVIÇO SOCIAL (CFESS). Código de ética profissional dos assistentes sociais 1947. Brasília: CFESS. Disponível em: <http:/www.cfess.org.br/ js/library/pdfjs/web/viewer.html?pdf=/arquivos/CEP_1947.pdf>. Acesso em: 4 set. 2016.

. Código de ética profissional do assistente social 1975. Brasília: CFESS. Disponível em: <http://www.cfess.org.br/js/library/pdfjs/web/viewer.html?pdf=/ arquivos/CEP_1975.pdf>. Acesso em: 4 set. 2016.

. Código de ética profissional do assistente social 1986. Brasília: CFESS. Disponível em: <http://www.cfess.org.br/js/library/pdfjs/web/viewer.html?pdf=/ arquivos/CEP_1986.pdf>. Acesso em: 4 set. 2016.

. Código de Ética Profissional do/a Assistente Social Lei n. 8.662/93. 10. ed. rev. e atual. Brasília: CFESS. Disponível em: <http://www.cfess.org.br/js/library/pdfjs/web/ viewer.html?pdf=/arquivos/CEP_CFESS-SITE.pdf>. Acesso em: 4 set. 2016.

IAMAMOTO M.; CARVALHO, R. De. Relações sociais e Serviço Social no Brasil: esboço uma interpretação histórico-metodológica. 4. ed. São Paulo/Lima: Cortez/ Celats, 1985.

LIMA, A. A. Serviço Social no Brasil: a ideologia de uma época. São Paulo: Cortez, 1983.

NETTO, J. P. Ditadura e Serviço Social: uma análise do Serviço Social no Brasil pós-64. São Paulo: Cortez, 1991.

- A construção do projeto ético-político do Serviço Social frente à crise contemporânea. Capacitação em Serviço Social e política social: crise contemporânea, questão social e Serviço Social, Módulo 1. Brasília: Cead/UnB-CFESS-Abepss, 1999. p. $91-110$. 